\title{
CONSIDERAÇÕES SOBRE AS MUDANÇAS CLIMÁTICAS GLOBAIS
}

\author{
José Bueno Conti ${ }^{1}$
}

\begin{abstract}
Resumo: A questão das mudanças climáticas globais vem sendo estudada com especial interesse pelos que se dedicam às ciências da natureza e da sociedade. Este artigo procura situar 0 assunto no limite entre essas duas esferas, assinalando a preocupação mundial em torno do problema, mas, ao mesmo tempo, mostrando as incertezas que o cercam e a necessidade de se aprofundar as pesquisas visando aprimorar, cada vez mais, 0 debate.
\end{abstract}

Palavras-chave: Efeito estufa, Aquecimento, Mudança climática, Dióxido de carbono, Vapor d'água.

\section{Introdução}

Durante 0 X Encontro de Geógrafos da América Latina (X EGAL), realizado em março de 2005, em São Paulo, o Professor Jorge Rabassa da Universidad Nacional de la Patagonia Austral, apresentou, na Mesa Redonda Mudanças Climáticas Globais: a América Latina no Contexto, uma exposição intitulada "El cambio climático global e su impacto en los glaciares de Patagônia, Tierra del Fuego y la Península Antártica". Rabassa comunicou, entre outros fatos, o rápido processo de degelo no Glaciar Upsala, um dos maiores do hemisfério sul e um processo equivalente, em curso, em importantes geleiras da Terra do Fogo. Este Termina seu texto afirmando: “...son excelentes ejemplos de esto, y triste y mudo testimonio de los daños ambientales producidos por la insensatez humana" (RABASSA, 2005).

Verifica-se tais ocorrências em latitude superior a $50^{\circ} \mathrm{S}$, em nosso continente, sendo estas apresentadas como exemplos das conseqüências do processo de aquecimento global. É mais um dado que se acrescenta ao esforço dos pesquisadores que, desde as investigações de Arrhenius (segunda metade do século XIX), vêm procurando demonstrar a associação entre a concentração de dióxido de carbono na atmosfera e elevação da temperatura. Isto ocorreria em virtude da capacidade de bloqueio desse gás sobre a radiação de onda longa procedente do planeta, produzindo o que se passou a chamar de efeito estufa. Este pesquisador sueco estudou, particularmente 0 dióxido de carbono $\left(\mathrm{CO}_{2}\right)$, mas há outros gases que produzem o mesmo resultado, tais como metano $\left(\mathrm{CH}_{4}\right)$, óxido nitroso $\left(\mathrm{N}_{2}\right)$, ozônio $\left(\mathrm{O}_{3}\right)$ clorofluorcarbonos (CFCs), etc., além de vários tipos de aerossóis. As substâncias citadas sofreram um significativo aumento em conseqüência da ação antrópica, tais como a queima de combustíveis fósseis, fruto da industrialização em grande escala; expansão de áreas urbanas; desmatamentos e queimadas de grandes volumes de biomassa; multiplicação do rebanho bovino, cujo processo digestivo libera metano; e também produzido pela decomposição do carbono em ambiente anaeróbico, como ocorre em pântanos e em reservatórios construídos para gerar hidroeletricidade à custa de submergir enormes extensões de florestas. 0 metano resultante da decomposição da madeira submersa vai ser liberado no momento da passagem de água pelas turbinas e sangradouros. 0 caso da hidroelétrica de Tucuruí, na Amazônia, foi claramente demonstrado em recente pesquisa do INPE - Instituto Nacional de Pesquisas Espaciais (FEARNSIDE, 2004). 0 óxido nitroso, por sua vez resulta de práticas agrícolas inadequadas.

Na última década, em ambos os hemisférios, não apenas exemplos de degelo, mas também de elevação significativa do nível do mar, excepcionalidades pluviométricas e barométricas, processos de desertificação, etc. vêm sendo apontados como fortes indícios desse processo, já que a concentração desses gases não cessa de crescer. Estudos do IPCC (Intergovernmental Panel of Climatic Change), entidade criada por iniciativa da ONU e da OMM (Organização Meteorológica Mundial), em 1988, para monitorar 0 problema e propor soluções mitigadoras, avaliam que, no último século, a temperatura média global aumentou em $0,6^{\circ} \mathrm{C}$. Nesse mesmo ano a Assembléia Geral da $\mathrm{ONU}$, em sua $70^{\mathrm{a}}$ Sessão Plenária, havia aprovado, em 06.12.88, uma resolução visando a "proteção do clima mundial para as gerações presentes e futuras" (apud ESCARDO, 1990).

\section{Ano Geofísico Internacional e o Observatório de Mauna Loa}

Entre os anos de 1957 e 1958, desenvolveu-se, sob a liderança dos Estados Unidos, o que se convencionou chamar, à época, de Ano Geofísico Internacional, durante 0 qual foram realizadas pesquisas, em

1 Professor Titular da Faculdade de Filosofia, Letras e Ciências Humanas da USP. 
todo 0 globo, de aspectos relativos às Ciências da Terra, envolvendo geologia, oceanografia, meteorologia, geofísica, etc., iniciativa pioneira na fase que sucedeu a Segunda Guerra Mundial. Um dos frutos desse esforço foi a instalação, em 1958, de um instrumento capaz de monitorar a concentração média de dióxido de carbono na atmosfera, no alto do vulcão Mauna Loa, no Havaí $(4.100 \mathrm{~m})$. 0 local foi escolhido por ser uma ilha isolada na vastidão do Pacífico e, portanto, afastada das grandes áreas urbanoindustriais do mundo, onde a liberação do $\mathrm{CO}_{2}$ é muito intensa. A partir dessa iniciativa, iniciaram-se os registros. Estes foram estendidos a outras áreas do globo, também localizados segundo os mesmo critérios, em Samoa (Pacífico tropical), Pólo Sul, Alasca, Canadá (província de Alberta), Tasmânia e na ilha de Tenerife, nas Canárias, este último, em 1984. A primeira medida de Mauna Loa indicou a proporção de 314 ppm (partes por milhão). Para se ter uma idéia comparativa assinala-se que, no começo da era industrial, no século XVIII, a concentração estimada de $\mathrm{CO}_{2}$ na atmosfera era de 290 ppm, tendo chegado, no ano 2003 a 336 ppm. Por outro lado, pesquisas glaciológicas, em bolhas de ar aprisionadas nas geleiras antárticas, há 800.000 mil anos (estimados), permitem admitir que a concentração não ultrapassasse $300 \mathrm{ppm}$, ou seja, a curva ascendente acentuou-se nos últimos 200 anos, notadamente, a partir dos anos 70 do século $\mathrm{XX}$.

Outros gases estufa também apresentaram crescimento significativo. Segundo fontes do IPCC, a quantidade de óxido nitroso, desde o final do século XVIII, cresceu $15 \%$ e a de metano, cerca de 2,3 vezes.

\section{Alguns indicadores do aquecimento global}

0 degelo nos Andes Meridionais, mencionado no início deste texto, constitui apenas um entre dezenas de outros exemplos que poderiam ser citados para mostrar a evidência do processo de aquecimento planetário e dos quais os meios de divulgação se ocupam com muita freqüência. Ocorrências de furacões em áreas não usuais, verões excessivamente quentes no hemisfério norte, estiagens severas em regiões habitualmente úmidas e outros distúrbios de sazonalidade, têm sido interpretados pela mídia e, mais cautelosamente, pela comunidade científica, como produtos da desestabilização climática.

O Professor Frédéric Bessat, da Universidade de Paris IV, no artigo, cuja tradução foi recentemente publicada no Brasil (BESSAT, 2003), baseado em modelos climáticos concebidos a partir dos gases de efeito estufa e aerossóis, identifica cinco tendências para 0 próximo século, que seriam as seguintes: aumento de $2,0^{\circ} \mathrm{C}$ na temperatura, em média, entre 1990 e 2100; elevação do nível do mar, de 0,50 a $0,80 \mathrm{~m}$ até 2.100 , com desarranjo no modelo de circulação das correntes oceânicas; aumento da precipitação de inverno nas latitudes mais elevadas; intensificação do ciclo hidrológico (maior incidência de secas e inundações) e perturbações no ciclo do carbono.

Conforme afirmou-se anteriormente, notícias são continuadamente divulgadas sobre degelo das calotas polares, redução das coberturas de neve das altas montanhas em várias latitudes, elevação do nível do oceano, verões extraordinariamente quentes, etc. Com base nesses dados, o estudioso francês Paul Acot do Centre National de Recherches Scientifiques (CNRS), da França, propôs duas hipóteses particularmente inquietantes: aumento da média térmica do globo de até $4,0^{\circ} \mathrm{C}$ até 2050 , afetando mais 0 hemisfério norte, em virtude da inércia térmica do hemisfério sul, predominantemente oceânico e aumento de, até 1 metro, ou mais, no nível dos oceanos, no mesmo período. Sabendo-se que $80 \%$ da população do mundo habita zonas costeiras, avalia-se o impacto de tal fenômeno (ACOT, 2003).

A elevação da temperatura global vem, efetivamente, ocorrendo, mas é indispensável avaliar as causas com base numa investigação abrangente, que leve em conta, não só a ação antrópica, representada pela liberação intensa de gases de efeito estufa, derrubada das florestas tropicais, superexploração da natureza desconsiderando os princípios da sustentabilidade, e outras práticas predatórias, mas, também, os processos naturais de macro-escala, incluindo os da esfera geológica e astronômica.

A mudança climática envolve um dinamismo mais complexo do que a simples elevação da média térmica, mesmo porque 0 clima não se define só pela temperatura. Contudo, a reação em cadeia que se estabelece a partir do aquecimento deve ser avaliada em profundidade.

Por outro lado, a alteração do perfil climático do globo, que se manifesta sob forma de tendências, rupturas e ciclicidades, faz parte da história do planeta e está documentado em relevos residuais, em depósitos sedimentares, em paleossolos, em formações vegetais relictuais, além de registros meteorológicos, disponíveis, ainda que em caráter pontual, desde 0 século XVII. 0 barômetro foi inventado em 1644 e o termômetro de mercúrio em 1709.

\section{A ação antrópica e o Protocolo de Kyoto}

A preocupação com os danos à atmosfera ganhou consistência a partir da década de 70 , quando a comunidade internacional foi alertada pelos estudiosos, sobre a destruição da 
camada de ozônio, situada a cerca de $50 \mathrm{~km}$ de altitude, que, como se sabe, protege o planeta da ação letal da radiação ultravioleta.

Iniciado naquele ano, por um sensor instalado no satélite Nimbus 7, o monitoramento da ozonosfera alarmou a humanidade pela demonstração da existência de um enorme buraco que logo se atribuiu aos clorofluorcarbonetos (CFCs) usado em refrigeradores $\mathrm{e}$ em outras aplicações industriais. A campanha internacional que se desencadeou em defesa da camada de ozônio culminou com a assinatura, pelos principais países do mundo, em 1988, do Protocolo de Montreal, cujo objetivo foi abolir 0 uso dos referidos gases a fim de proteger a vida na Terra.

Poucos anos após, estudos demonstram que os gases responsáveis pela destruição da camada de ozônio são também produzidos por processos naturais que, talvez, sejam até mais relevantes. 0 Professor Luiz Carlos B. Molion publicou um artigo, em 1992, no qual chama atenção para o papel dos gases lançados pela atividade vulcânica, entre os quais há, além de enxofre, enormes volumes de cloro, flúor e bromo, que também concorrem para danificar a camada de ozônio em proporções muito significativas. Ele assinala ainda que a produção fotoquímica de ozônio depende da radiação ultravioleta do sol, a qual, por sua vez, obedece a ciclos de 11 anos. 0 Protocolo de Montreal, portanto, teria uma eficácia limitada (MOLION, 1992).

No caso dos gases de efeito estufa, o acordo se fez em torno do chamado Protocolo de Kyoto, lançado durante a conferência da Convenção do Clima realizado naquela cidade japonesa, em 1997, mas posto em vigor, efetivamente, só a partir de 2005.

0 que vem a ser esse tratado?

Fundamenta-se na hipótese de que 0 aquecimento global, causado, como se sabe, pelos gases bloqueadores da radiação de onda longa (dióxido de carbono, metano, óxido nitroso ozônio e outros), seria controlado mediante o compromisso internacional de uma gradativa redução do lançamento dessas substâncias na atmosfera. Baseia-se, ainda, em um pressuposto ético: o princípio da responsabilidade comum quanto se trata da defesa da natureza.

Este tratado exige que os países mais industrializados, os maiores geradores desses gases, restrinjam suas emissões em $5,2 \%$, até 2012 , com base nos níveis de 1990 , estabelecendo sanções para os não cumpridores. Relacionou esses países, no chamado Anexo I, totalizando 41, todos no hemisfério norte, com exceção da Austrália e Nova Zelândiaª . Os demais ficariam, provisoriamente fora do Protocolo e poderiam ser beneficiados com o Mecanismo de Desenvolvimento Limpo (MDL), modelo que tem sido bem sucedido. Propõe aos países industrializados a troca da redução das emissões de gases em seus territórios por investimentos em projetos de energia renovável e de absorção de carbono, também chamados de "sumidouros de carbono" em países em desenvolvimento. Aos países que tiverem essa iniciativa serão conferidos "créditos de carbono" ou aumento permitido de suas cotas de emissão. Proporciona, portanto, ganhos mútuos, pois foi concebido de forma inteligente favorecendo não só os grandes emissores, mas também os países menos industrializados como 0 nosso. Várias iniciativas empresariais já estão em curso, no Brasil, com base no Mecanismo do Desenvolvimento Limpo. 0 projeto pioneiro é o da empresa NovaGerar, em Nova Iguaçu (RJ) com capitais do Banco Mundial e da Holanda, que se propõe a transformar biogás, liberado por aterro sanitário, em energia elétrica. Este foi o primeiro projeto aprovado no mundo, dentro do modelo preconizado pelo MDL e, até o fim de 2005, mais 30 outros deverão ser aprovados pelo Banco Mundial em nosso país.

0 Protocolo entrou em vigor no dia 16 de fevereiro de 2005, dois meses após ter sido assinado pela Rússia $(17,4 \%$ das emissões), completando o mínimo de 55 países que representam pelo menos $55 \%$ das emissões de gases de efeito estufa, conforme dispunha 0 documento. Os Estados Unidos, maiores emissores mundiais $(36,1 \%)$, negaram-se a aderir sob 0 argumento de que isso afetaria significativamente sua economia, recusa que, evidentemente, torna frágil a eficiência do Protocolo. 0 Brasil já havia aderido em 23 de julho de 2002 (data da sanção presidencial). Mesmo antes da assinatura, o governo brasileiro havia tomado medidas relevantes. Em 1999, fora criada uma Comissão Interministerial da Mudança Global do Clima, parceria entre os Ministérios da Ciência e Tecnologia e do Meio Ambiente para propor uma política de mitigação dos efeitos das mudanças climáticas e de adaptação aos seus impactos.

Já se prevê uma fase pós-Kyoto, quando países emergentes como Brasil, Índia, China e México terão aumentado muito suas emissões, podendo ultrapassar alguns dos países hoje incluídos no Anexo I. No caso do nosso país, é o desmatamento e a queima de florestas tropicais que concorrerão substancialmente para aumentar as taxas de emissão. Essas e outras questões deverão ser discutidas na

2 Alemanha, Austrália, Áustria, Bielo-Rússia, Bélgica, Bulgária, Canadá, Croácia, Dinamarca, Eslováquia, Eslovênia, Espanha, EUA, Estônia, Finlândia, França, Grécia, Holanda, Hungria, Irlanda, Islândia, Itália, Japão, Letônia, Liechtenstein, Lituânia, Luxemburgo, Mônaco, Nova Zelândia, Noruega, Polônia, Portugal, Reino-Unido e Irlanda do Norte, República do Norte, República Checa, Romênia, Rússia, Suíça, Turquia e Ucrânia.

Conferência das Partes, prevista para novembro de 2005, em Montreal, fórum que reúne os países signatários da Convenção 
Quadro das Nações Unidas sobre Mudança Climática, conhecida como Convenção do Clima, a qual, por sua vez, derivou de acordos acertados na Conferência do Rio de Janeiro em 1992, a RIO-92.

Há, contudo, questionamentos levantados quanto a eficácia do Protocolo de Kyoto para o controle do clima global, em primeiro lugar devido à negativa dos Estados Unidos, já citada. Mesmo no que diz respeito ao MDL há aspectos insatisfatoriamente resolvidos. Os planos de reflorestamento para "seqüestrar" carbono, por exemplo, não são uma garantia de que, mais cedo ou mais tarde, o $\mathrm{CO}_{2}$ estocado não seja novamente liberado de volta à atmosfera. Deve-se lembrar que, mesmo após a estabilização do lançamento dos gases nocivos, estes permanecerão por dezenas de anos, já que têm um efeito duradouro na composição da atmosfera. $0 \mathrm{CO}_{2}$, por exemplo, tem seu tempo de "vida" na atmosfera estimado no mínimo em 50 anos, e, no máximo em 200.

\section{0 papel da natureza no aquecimento global e a relevância do vapor d'água.}

Não constitui matéria deste artigo tratar da evolução paleo-climática do globo desde suas origens, mas trazer algumas considerações sobre 0 que se passa no período recente, após a Primeira Revolução Industrial. Nessa perspectiva, a mudança climática pode estar sofrendo influência expressiva de processos derivados da natureza, processos estes ainda não convenientemente avaliados e a ação antrópica constituiria, tão somente, fator agravante.

É oportuno lembrar que o efeito estufa é um fenômeno natural, sem 0 qual a temperatura média do planeta, hoje em torno de $15^{\circ} \mathrm{C}$, desceria para $-18^{\circ} \mathrm{C}$, tornando inviável a permanência da biosfera tal como hoje a conhecemos e este efeito não resulta somente de gases produzidos pela atividade humana. Estes contribuem com apenas $40 \%$ do total, cabendo ao dióxido de carbono $25 \%$ e $15 \%$ aos demais. É o vapor d'água, com $60 \%$ de participação, 0 agente mais ativo do efeito estufa, presente em diferentes faixas de absorção da radiação infravermelha (onda longa), colaborando de forma preponderante no processo de aquecimento planetário e seu volume, na atmosfera, independe da ação humana. Origina-se da radiação solar incidindo sobre as superfícies líquidas e transformando a água, do estado líquido para 0 de vapor. As baixas latitudes (menores que $30^{\circ}$ ) recebem cinco vezes mais energia solar que aquelas situadas além de $60^{\circ}$ e esse calor se concentra nos oceanos (apenas $24 \%$ das terras emersas situam- se na zona intertropical), intensificando significativamente a evaporação. A dinâmica geral da atmosfera encarrega-se de distribuir esse vapor por todo o planeta robustecendo 0 efeito de estufa global. 0 Protocolo de Kyoto, embora tenha sido uma iniciativa muito oportuna da comunidade internacional no sentido de adotar mecanismos de preservação da qualidade ambiental, não contempla esse dado importante, mesmo porque este se encontra fora de controle. A maioria dos eventos que trata do assunto e os inúmeros textos que se publicam a respeito, surpreendentemente, não avaliam, de forma adequada, o papel do vapor d'água no processo de aquecimento do planeta, superestimando, no nosso entender, a responsabilidade dos gases produzidos pela ação antrópica, os quais, como vimos, têm, percentualmente, uma participação menor.

Por outro lado, o fenômeno poderia, também, estar associado às variações cíclicas do albedo planetário, ou seja, a entrada de radiação de onda curta, hipótese defendida pelo Professor Molion, anteriormente citado. A redução da reflectância (ou albedo) produziria maior input de radiação de onda curta e, portanto, elevaria a quantidade de energia disponível na atmosfera terrestre. $\mathrm{Na}$ continuação do raciocínio, afirma o estudioso, como os oceanos se aqueceriam durante 0 período de baixo albedo planetário, parte do dióxido de carbono liberado por essa atividade não chegaria a ser absorvida por esse ambiente durante 0 processo de reciclagem do carbono, uma vez que a solubilidade do referido gás, num líquido, é inversamente proporcional à sua temperatura, ficando 0 excedente armazenado na atmosfera (MOLION, 2001).

0 agravamento do efeito estufa poderia, também, vincular-se à baixa atividade vulcânica dos últimos 15 anos, e isso tenderia a elevar a temperatura média do globo já que 0 inverso, conforme se demonstra sempre que há uma grande erupção, produz efeito contrário.

\section{Conclusão}

Há muitas perguntas para as quais ainda não se tem respostas satisfatórias. 0 relatório divulgado pelo IPCC em 2005 indica que a elevação da temperatura atinge diferentemente as diversas regiões do planeta. Em alguns pontos vêm se registrando o oposto, ou seja, uma tendência negativa das médias térmicas ao longo de décadas, provavelmente em função de fatores locais. 0 Professor Giorgio Giacaglia, do Instituto Astronômico e Geofísico da USP, em pesquisa dos anos 70, indicou a probabilidade de o globo estar caminhando para uma nova idade do gelo em decorrência de alterações na atividade solar (GIACAGILA, 1974). Também do mesmo Instituto, o Prof. Pedro Leite da Silva Dias, informa que "os relatórios do IPCC apontam para grandes dificuldades na detecção dos sinais de 
mudança climática de origem antrópica em função da alta variabilidade natural do clima" e que existem "grandes incertezas quanto aos efeitos regionais, particularmente na América do Sul onde existe um enorme estoque de carbono armazenado no solo e na parte aérea da floresta amazônica" (SILVA DIAS, 2005).

Outros pesquisadores especulam sobre uma possível retomada da atividade vulcânica, que, ao lançar poeira e aerossóis na atmosfera poderia neutralizar o efeito estufa e concorrer para um abaixamento da temperatura média do planeta. A avaliação, portanto, deve ser feita de forma cuidadosa, e em diferentes escalas, sendo plausível a hipótese de uma oscilação climática de grande amplitude, porém manifestando-se diferentemente nos diversos pontos do globo.

A questão das mudanças climáticas precisa, portanto, passar por uma apreciação mais refinada a fim de que se possa determinar, com maior consistência, o papel da natureza e 0 da ação humana no processo, mesmo porque as duas esferas podem atuar de forma solidária e intercambiar influências.

Cenários de catástrofes, freqüentemente apresentados na mídia de forma simplista, sem o necessário questionamento, devem ser descartados, pois, seguramente, o planeta não está caminhando para o colapso, em curto prazo, e ainda não dispomos de informações seguras para previsões muito distantes. Por outro lado, há uma propensão nítida de mudança na matriz energética mundial, tendendo os combustíveis fósseis, acusados de responsáveis pelo efeito estufa, a ocupar lugar mais modesto, em favor de energias limpas e renováveis. Importantes investimentos vêm sendo feitos, nesse sentido, por iniciativa empresarial e na esfera das políticas públicas. Não obstante esses aspectos positivos, medidas cautelares tomadas no plano internacional, visando restringir a liberação de gases, como as preconizadas pelo Protocolo de Kyoto, são bem-vindas, pois é chegado o momento de se traçar uma estratégia comum em favor da natureza. Trata-se de diretriz que, acima de tudo, encerra um forte conteúdo educativo.

Não se desconhece que o componente político e, sobretudo, 0 econômico são da maior relevância. No caso do Protocolo de Montreal sobre os clorofluorcarbonos (1988), ainda pairam suspeitas sobre se não teria sido estimulado por grandes empresas interessadas em produzir gases alternativos aos CFCs e, mais recentemente, a recusa dos EUA em aderir ao Protocolo de Kyoto deixa claro que a lei do mais forte ainda prevalece.

O Professor Jorge Oscar Rabassa, citado no início deste artigo, adverte que o derretimento atípico das geleiras da Patagônia resulta da "insensatez humana". Diríamos nós que, enquanto geógrafos, devemos exercer um papel formador, enfatizando a importância da solidariedade entre os grupos humanos em defesa do patrimônio planetário comum. Os geógrafos, ao lado de outros estudiosos das ciências humanas, têm diante de si 0 desafio de conduzir a reflexão sobre o significado da natureza e de seu papel enquanto suporte da sociedade. 
CONTI, J. B. (2005). On global climatic changes. Revista do Departamento de Geografia, n. 16, p. 70-75.

Abstract: The question of global climatic changes has been studied with special interest by the ones who devote themselves to nature and society sciences. This paper intends to place the subject at the limit between these two spheres, emphasizing the world's worries around this problem, but at the same time, showing uncertainties that surround it and the necessity of going deeper into the researches, aiming to improve, ever more, the debate.

Key words: Greenhouse effect, Warming, Climatic change, Carbon dioxide, Water vapor.

Recebido em 7 de setembro de 2005, aceito em 2 de outubro de 2005.

\section{Referências}

ACOT, P. (2003) Histoire du climat. Paris, Éditions Perrin, 309p.

BESSAT, F. - F. (2003) A mudança climática entre ciência, desafios e decisões: olhar geográfico. In: Terra Livre. São Paulo, Associação dos Geógrafos Brasileiros. Ano 19, vol I, n. 20. p. 11-26.

ESCARDO, A.L. (1990) Cambios en el sistema climático. Una aproximación al problema. Madrid, OMM, Série A-136. 125p.

FEARNSIDE, P.M. (2004) Gases de efeito estufa em hidrelétricas da Amazônia.In: Ciência Hoje. São Paulo, Sociedade Brasileira para o Progresso da Ciência, v. 36, n. 211. p. 41-44.

GIACAGLIA, G.E.O (1974) A Terra caminha para nova era glacial. O Estado de São Paulo, São Paulo. 30/06/1974.

MOLION, L.C.B. (1992) 0 buraco de ozônio: o outro lado da história. In: Boletim da Sociedade Brasileira de Meteorologia, São Paulo, vol. 16, nº 1. p. 8-11.
MOLION, L.C.B. (2001) Aquecimento global: fato ou ficção? In: Revista do Instituto Brasileiro de Edições Pedagógicas Geografia, São Paulo, ano I, n ${ }^{0}$ 4. p. 6-9.

RABASSA, J.O. (2005) El cambio climático y su impacto en los glaciares de Patagonia, Tierra del Fuego y la peninsula Antartica. In: $10^{\circ}$ Encontro de Geógrafos da América Latina, São Paulo. Resumos, São Paulo, Universidade de São Paulo, Faculdade de Filosofia Letras e Ciências Humanas, p. 48.

SILVA DIAS, P.L. (2005) Mudanças climáticas; como conviver com as incertezas sobre os cenários futuros. In $10^{\circ}$ Encontro de geógrafos da América Latina, São Paulo. Resumos, São Paulo, Universidade de São Paulo, Faculdade de Filosofia, Letras e Ciências Humanas. p. 47-48. 